\title{
O PERFIL DAS PUBLICAÇÕES DO CONGRESSO UFSC DE INICIAÇÃO CIENTÍFICA EM CONTABILIDADE
}

\author{
Fabiane da Silva Medeiros ${ }^{1}$, Denize Demarche Minatti Ferreira ${ }^{2}$, Alessandra Rodrigues Machado de Araujo ${ }^{3}$ \\ ${ }^{1,2,3}$ Universidade Federal de Santa Catarina \\ ${ }^{1}$ fabiufscohotmail.com \\ ${ }^{2}$ denize.minattidusfc.br \\ 3 alermdearaujo@hotmail.com
}

\section{Resumo}

Observa-se um aumento considerável na produção científica brasileira na área contábil, em que a busca por conhecimento científico parte da pesquisa para a posterior divulgação. Neste contexto, tem-se como objetivo investigar o perfil das publicações nas seis edições do Congresso UFSC de Iniciação Científica em Contabilidade, que foram realizados no período compreendido entre 2007 e 2015. A metodologia utilizada foi predominantemente quantitativa, descritiva e bibliométrica. A população da pesquisa contempla todos os 314 artigos publicados nos anais do congresso. Dentre os principais achados destaca-se a predominância de artigos com dois e três autores, a Universidade Federal de Santa Catarina (UFSC) como instituição mais prolífica com 104 artigos apresentados, seguida pela Universidade Federal de Uberlândia (UFU) com 46 artigos. Ainda em relação aos resultados, a titulação máxima dos autores foi a graduação e doutorado e, as autoras mais produtivas são Edvalda Araújo Leal (UFU) e Sandra Rolim Ensslin (UFSC) ambas publicaram 11 artigos. A abordagem mais utilizada foi a qualitativa (119) com relação ao problema e, descritiva (169) relacionada ao objetivo e a Contabilidade Pública Governamental foi o sub tema mais escolhido (26 artigos). Conclui-se com esta pesquisa que há temas em Contabilidade para serem explorados pelos futuros pesquisadores, avançando na produção científica e na disseminação do conhecimento.

Palavras-chave: Produção Científica. Bibliometria. Contabilidade.

\section{PROFILE OF PUBLICATIONS OF THE UFSC SCIENTIFIC INITIATION CONGRESS IN ACCOUNTING}

\begin{abstract}
It is observed a considerable increase in the Brazilian scientific production in the accounting area, in search of scientific knowledge part of the scientific research for a later disclosure. In this context, it aims to investigate the profile of publications in the six editions of the UFSC Congress of Scientific Initiation in Accounting, which were carried out from 2007 to 2015. A methodology for predominantly quantitative, descriptive and bibliometric. The research population includes all 314 articles published in the Congressional record. Among the main findings highlight the predominance of articles two and three authors, the Federal University of Santa Catarina (UFSC) was the most prolific institution with 104 papers presented, followed by the Federal University of Uberlandia (UFU) with 46 articles. Also in relation to the results, the maximum degree of the authors was to graduate and doctorate and the most productive authors are Edvalda Araújo Leal (UFU) and Sandra Rolim Ensslin (UFSC) both published 11 articles. The
\end{abstract}


most widely used approach was qualitative (119) with respect to the problem and descriptive (169) related to the goal and the Public Accounts Government was the sub theme choicest (26 articles). The conclusion of this research is that there are several issues in accounting to be explored by future researchers, advancing the scientific production and dissemination of knowledge.

Keywords: Scientific Production. Bibliometrics. Accounting.

\section{Introdução}

As publicações de trabalhos acadêmicos, seja em eventos ou periódicos, buscam difundir reflexões e conhecimentos além de promover debates sobre diferentes temas de caráter científico. A produção científica mostra-se como principal instrumento para a construção de ideias, inovação e expansão das pesquisas, por meio de análises e estudos realizados nas universidades com a função de propagar o saber em todas as vertentes da ciência (CASAGRANDE et al., 2012).

Dois importantes benefícios da pesquisa são destacados por Cunha, Cornacchiore e Martins (2011), o desenvolvimento científico da área com benefícios à sociedade de modo geral e o uso da pesquisa como procedimento de ensino. Segundo Leite Filho (2008), a pesquisa em contabilidade enfrenta um processo de expansão do conhecimento, em que se observa maior evidência desde o ano 2000. Fato esse explicado por Silva (2005) e Souza et al. (2008), como sendo devido ao aumento de programas de pós-graduaçao em contabilidade no Brasil.

As pesquisas bibliométricas podem auxiliar e contribuir para estudos futuros no ponto que a bibliometria irá compilar os dados de pesquisas anteriores em determinadas áreas da ciência e observar possíveis lacunas e/ou ideias a partir de uma análise. Segundo Chueke e Amatucci (2015, p.2), "no campo das ciências sociais aplicadas, os estudos bibliométricos se concentram em examinar a produção de artigos em um determinado campo de saber, mapear as comunidades acadêmicas e identificar as redes de pesquisadores e suas motivações".

Baseado nas informações anteriores surge como questão orientadora desta pesquisa: Qual o perfil das publicações das seis edições do Congresso UFSC de Iniciação Científica em Contabilidade?

Deste modo, o objetivo principal desta pesquisa é investigar o perfil das publicações relacionadas nas seis edições do Congresso UFSC de Iniciação Científica em Contabilidade, que foram realizados no período compreendido entre 2007 e 2015. Com a finalidade de atender a este objetivo será levantado, por meio de pesquisa bibliométrica, (i) a quantidade de artigos, (ii) as linhas de pesquisas mais recorrentes, (iii) as instituições mais produtivas, bem como (iv) as metodologias aplicadas nos artigos.

O estudo contribui em termos teóricos para a ampliação da compreensão das características da pesquisa contábil por meio de um congresso específico. A pesquisa está delimitada ao período compreendido entre 2007 e 2015 nos artigos apresentados no Congresso UFSC de Iniciação Científica em Contabilidade, não podendo, portanto, serem os resultados generalizados.

\section{Referencial Teórico}

Para dar suporte teórico à pesquisa, apresentam-se neste tópico os temas Produção Científica em Contabilidade, Estudos Bibliométricos e Estudos Anteriores. 


\subsection{Produção Científica em Contabilidade}

A comunicação científica é imprescindível para a comunidade acadêmica, sem ela a ciência não existiria, ela pode ser entendida como um conjunto de práticas relacionadas à propagação e ao uso da informação (OLIVEIRA, 2002). Segundo Casagrande et al. (2012), tem-se a pesquisa como atividade que propicia a construção de ideias, inovação, ampliação e disseminação do conhecimento, podendo ser feita por meio de publicações em periódicos, congressos, livros, entre outros.

Brunozi Júnior et al. (2011) observam que por intermédio de periódicos e outros meios de divulgação, a produção científica é levada aos leitores possibilitando um maior avanço no desenvolvimento científico. Frezatti e Borba (2000, p.51) relatam que:

As publicações em órgãos especializados constituem esforço importante na carreira dos pesquisadores no sentido de proporcionar a exteriorização do pensamento e produção. Num mundo globalizado, com recursos eletrônicos como aqueles de que dispomos, a comunicação se torna mais rápida, intensa, e a demanda por informações se torna muito forte no sentido de evitar perda de tempo "redescobrindo a roda", sendo de se considerar ainda a redução de prazo na geração de trabalhos e o aprimoramento do nível de uma dada pesquisa.

Segundo Oliveira e Boente (2012), observa-se um aumento considerável na produção científica brasileira na área contábil, "sobretudo aquela evidenciada por meio de canais de comunicação científica, compreendendo periódicos especializados e congressos acadêmicos" (LUCA et al., 2011, p. 146). Para Silva, Oliveira e Ribeiro (2005) e Souza et al. (2008), a expansão da pesquisa em contabilidade pode ser explicada pelo aumento de programas de pósgraduaçao em contabilidade no Brasil.

A produção científica em contabilidade provêm em sua maior parte do que é produzido de trabalhos realizados nos cursos de pós-graduação. Tem-se por meio dessa produção o aumento da divulgação do conhecimento, permitindo a propagação da Ciência Contábil como ramo do conhecimento que busca prover seus usuários de informações úteis, tempestivas e auxiliares do processo decisório (SILVA et al., 2005).

De acordo com estudo de Leite Filho (2008), a maioria da produção acadêmica nos periódicos da área de Ciências Contábeis, apresentam-se como trabalhos de um autor, dando indícios de que os pesquisadores tendem a publicar de forma isolada. Tem-se ainda a predominância de autores do sexo masculino na publicação da área, assim como indícios de forte endogenia de instituições nacionais.

Segundo estudo de Borba e Murcia (2006), o maior número de artigos publicados em revistas do Portal de Periódicos da Capes é na área de Contabilidade Financeira. Corroborando, Mendonça Neto et al. (2004) afirmam ainda que os autores nacionais da área contábil apresentam uma baixa produtividade em relação aos autores internacionais, em que a participação da produção científica em contabilidade representa $2,95 \%$ do total de artigos publicados nas revistas de conceito A da Capes. Com base nesses achados, reforça-se a lenta disseminação do conhecimento científico em contabilidade no âmbito nacional.

\subsection{Estudos Bibliométricos}

Segundo Vanti (2002) e Araújo (2007) os estudos bibliométricos tiveram início no começo do século passado, com a composição das três principais leis clássicas da Bibliometria: a lei de Lotka (medição da produtividade dos pesquisadores); a lei de Bradford (mediante a medição da 
produtividade dos periódicos, estabelece o núcleo e os temas mais recorrentes); e a lei de Zipf (frequência das palavras). De acordo com Araújo (2007), essas leis sofreram variações de enfoques bibliométricos no decorrer dos anos.

A avaliação da qualidade de um artigo científico, ou mesmo a produção científica de um determinado autor, pode ser feita por meio de indicadores bibliométricos. Tais indicadores de desempenho são úteis para avaliar a pesquisa acadêmica, orientar rumos e estratégias de financiamento de pesquisas (CAMPOS, 2003).

Tem-se ainda, de acordo com Vanti (2002), que a bibliometria é um conjunto de métodos de pesquisa da área das Ciências da Informação por meio de uma análise quantitativa de dados. Método esse que possibilita além de mapear a estrutura de um campo científico, analisar o comportamento dos pesquisadores em suas decisões na construção deste conhecimento.

Para Cardoso et al. (2005, p.35), mapear e compreender as pesquisas científicas por meio de revisões estruturadas possibilita a análise e a reflexão desses trabalhos em determinada área. Consoante a este pensamento, Oliveira e Carvalho (2008, p.14) afirmam que:

A informação produzida no meio acadêmico tem um valor extra se olhada como indicador direto da produção do conhecimento humano. Além disso, espera-se que o corpo docente e o discente [...] estejam integrados em projetos de pesquisas, culminando os achados dessas pesquisas em publicações. É nesse contexto que emerge a bibliometria, em face de as publicações serem quantificadas por autor, por tipo de revista, por programa, entre outras.

Os estudos bibliométricos contribuem na função de sintetizar os dados das pesquisas publicadas em determinadas áreas, compilando informações e direcionando problemas para futuramente servirem de objeto de investigação aos pesquisadores, tornando de forma gradual o desenvolvimento do conhecimento científico (CHUEKE; AMATUCCI, 2015).

Figueiredo (1990) aponta ainda dois papeis relevantes desse tipo de estudo, a sua função histórica e de atualização. A função histórica por constituir-se em parte integral do desenvolvimento da ciência. Já a função de atualização por fornecer aos profissionais de diferentes áreas, informações acerca de determinada ciência e sua literatura. Observa-se aqui, o cumprimento desses papeis nas pesquisas bibliométricas em contabilidade, no qual a presente pesquisa se enquadra.

\subsection{Estudos Anteriores}

Com uma revisão literária no âmbito nacional, observam-se estudos relacionados à bibliometria, o Quadro 1 apresenta pesquisas semelhantes ao propósito desta pesquisa, com os objetivos e os principais resultados obtidos.

Quadro 1: Estudos anteriores

\begin{tabular}{|l|l|l|}
\hline Autor/Ano & Objetivo Principais Resultados \\
\hline $\begin{array}{l}\text { ARAUJO et al.. } \\
2015\end{array}$ & $\begin{array}{l}\text { Investigar o perfil das publicações em } \\
\text { português com o tema governança } \\
\text { ambiental em revistas indexadas pelo } \\
\text { Portal Capes, SciELO e Spell. }\end{array}$ & $\begin{array}{l}\text { Foram analisados 17 artigos, em 14 periódicos, } \\
\text { entre 2002 e 2014. Conclui-se então no presente } \\
\text { estudo que a inserção da governaça ambiental nas } \\
\text { publicações dos periódicos analisados ainda é } \\
\text { pouco significativa, necessitando de mais estudos. }\end{array}$ \\
\hline
\end{tabular}




\begin{tabular}{|c|c|c|}
\hline $\begin{array}{l}\text { ANZILAGO } \\
a l ., 2015\end{array}$ & $\begin{array}{l}\text { Investigar o perfil das publicações na } \\
\text { Conferência sobre Pesquisa Social e } \\
\text { Contabilidade Ambiental - CSEAR, South } \\
\text { América nas últimas edições realizadas em } \\
2009,2011 \text { e } 2013 \text {. }\end{array}$ & $\begin{array}{l}\text { As instituições mais prolíferas são USP, UFSC, } \\
\text { UFBA e UFRJ. Os resultados contribuem como } \\
\text { aprofundamento dos trabalhos apresentados no } \\
\text { CSEAR, identificando lacunas na pesquisa sobre } \\
\text { sustentabilidade e abrindo caminho para as } \\
\text { publicações em outras abordagens e temáticas. }\end{array}$ \\
\hline SANTOS, 2015 & $\begin{array}{l}\text { Apresentar uma análise dos artigos } \\
\text { publicados como estudos bibliométricos } \\
\text { no Congresso Brasileiro de Custos }(\mathrm{CBC})\end{array}$ & $\begin{array}{l}\text { Os resultados demonstraram que foram publicados } \\
55 \text { artigos no CBC. A instituição de ensino mais } \\
\text { prolífera foi a UFSC, com } 25 \text { autores, seguida pela } \\
\text { UFU (20) e USP (18). Tiveram } 1.449 \text { referências, } \\
\text { as nacionais são as mais usuais ( } 72 \% \text { ). E as fontes } \\
\text { de pesquisas mais usadas são as revistas, com } 585 \\
\text { referências, seguidas dos livros com } 457 \text {. }\end{array}$ \\
\hline RIBEIRO, 2013 & $\begin{array}{l}\text { Verificar as características da produção } \\
\text { científica dos artigos na área temática } \\
\text { controladoria e contabilidade gerencial no } \\
\text { Congresso USP no período de } 2001 \text { a } \\
2011 .\end{array}$ & $\begin{array}{l}\text { O perfil macro das publicações e da evolução da } \\
\text { área temática controladoria e contabilidade } \\
\text { gerencial analisam variáveis com o intuito de } \\
\text { nortear e, contribuir para a melhor compreensão, } \\
\text { melhoria e fomento dos artigos publicados sobre a } \\
\text { área temática, ora investigada no meio acadêmico. }\end{array}$ \\
\hline $\begin{array}{l}\text { FERREIRA; } \\
\text { ROSA; BORBA, } \\
2012\end{array}$ & $\begin{array}{l}\text { Realizar levantamento dos periódicos de } \\
\text { língua inglesa e portuguesa, disponíveis no } \\
\text { Portal de Periódicos da } \\
\text { apresentassem teres, que } \\
\text { relacionados à questão ambiental. }\end{array}$ & $\begin{array}{l}\text { Constatou-se existência de espaço para pesquisas na } \\
\text { área de Ciências Sociais Aplicadas e sua relação } \\
\text { com o meio ambiente no Brasil, visto que somente } \\
\text { um periódico relacionado aos termos examinados } \\
\text { está disponível. }\end{array}$ \\
\hline $\begin{array}{l}\text { MACHADO; } \\
\text { SILVA; } \\
\text { BEUREN, } 2012\end{array}$ & $\begin{array}{l}\text { Identificar características da produção } \\
\text { científica de custos, publicada } \\
\text { periódicos nacionais } \\
\text { Qualis/CAPES, sob a perspectiva } \\
\text { redes das } \\
\text { reciais e da bibliometria. }\end{array}$ & $\begin{array}{l}\text { Os resultados evidenciam aspectos interessantes da } \\
\text { produção científica na área de custos, que podem } \\
\text { ser ampliados em futuras investigações sobre essa } \\
\text { temática. }\end{array}$ \\
\hline $\begin{array}{l}\text { SILVA et al., } \\
2012\end{array}$ & $\begin{array}{l}\text { Mapear redes de colaboração científica, } \\
\text { em periódicos, dos docentes de programas } \\
\text { de Pós-Graduação em Contabilidade de } \\
2007 \text { a 2009, identificando autores, } \\
\text { vínculos, interações e grau de } \\
\text { centralização das redes de colaboração. }\end{array}$ & $\begin{array}{l}\text { Conclui-se que a maioria dos programas tem } \\
\text { contribuído para a evolução das pesquisas e } \\
\text { publicações científicas na área contábil, e, para } \\
\text { tanto, tem-se utilizado parcerias colaborativas no } \\
\text { desenvolvimento de suas pesquisas. }\end{array}$ \\
\hline $\begin{array}{l}\text { LEITE FILHO, } \\
2008\end{array}$ & $\begin{array}{l}\text { Analisar a produtividade científica dos } \\
\text { autores em anais de congressos e periódica } \\
\text { brasileiros na área de Contabilidade. }\end{array}$ & $\begin{array}{l}\text { Os principais resultados evidenciaram uma } \\
\text { padronização de publicação, a predominância de } \\
\text { autores do sexo masculino, indícios de forte } \\
\text { endogenia de instituições nacionais, existência de } \\
\text { concentração de autoria vinculada a poucas } \\
\text { instituições que apresentaram as mais altas } \\
\text { frequências relativas nos veículos de publicação. }\end{array}$ \\
\hline
\end{tabular}

Fonte: Autores (2017) 
Importante ressaltar que as pesquisas apresentadas foram realizadas em diversas áreas de comunicação científica (eventos e periódicos), destacando que o objeto desse estudo é o Congresso UFSC, em que os resultados expressos auxiliam no entendimento da pesquisa.

\section{Metodologia da Pesquisa}

A presente pesquisa é classificada como predominantemente quantitativa com relação ao problema, Michel $(2009$, p.37) relata que a "a pesquisa quantitativa parte do princípio de que tudo pode ser quantificável, ou seja, que opiniões, problemas, informações, serão mais bem entendidas se traduzidas em formas de números". Constituindo-se de uma coleta de dados quantitativos dos artigos e a tabulação desses, assegurando a exatidão dos resultados.

Apresenta-se como uma pesquisa descritiva com relação aos objetivos, pois tem o objetivo de identificar o perfil das publicações do determinado Congresso, desta forma serão observados, registrados, analisados e relacionados diversos aspectos dos artigos apresentados no Congresso (CERVO; BERVIAN; SILVA, 2007). Segundo Gil (2010, p.27) "as pesquisas descritivas têm como objetivo a descrição das características de determinada população”.

Neste caso, a população da pesquisa contempla todos os 314 artigos publicado nos anais das seis edições do Congresso UFSC Iniciação Científica em Contabilidade e disponibilizados por meio do endereço eletrônico do evento, compreendendo o período de 2007 a 2015.

A pesquisa classifica-se como bibliométrica, visto que trata de um estudo sobre os artigos publicados nos anais do Congresso UFSC. De acordo com Ukubo (1997, p.6), esta "é uma ferramenta com a qual o estado da ciência e da tecnologia podem ser observados por meio de investigação pormenorizada da produção da literatura científica, em certo nível de especialização".

Com a finalidade de identificar o perfil das publicações do Congresso UFSC de Iniciação Científica em Contabilidade foram analisadas as seguintes características: (i) composição de autoria, com a média de autores por ano; (ii) dispor as autorias por instituição, unidade federativa, titulação e apontar os autores mais produtivos; (iii) linhas temáticas mais publicadas, baseada nas áreas temáticas definidas pelo respectivo Congresso; (iv) evidenciar as abordagens metodológicas com relação ao problema e ao objetivo dos artigos apresentados no Congresso, identificados pelos próprios autores.

Utilizar-se-á ainda para o alcance dos objetivos deste estudo, a ferramenta online: Plataforma Lattes a fim de complementar as informações sobre a autoria, uma vez que não constavam referências dos autores no corpo dos artigos. Com o propósito de obter dados reais à data dos eventos, utilizaram-se as informações dos autores referentes aos anos onde suas publicações ocorreram. Os autores não localizados na Plataforma Lattes serão mencionados como "Não Identificada".

Com relação às palavras-chaves além do Software Microsoft Excel ${ }^{\circledR}$ por conveniência recorreu ao uso de outras ferramentas online Wordle.net $^{\circledR}$ e Tagul.com $^{\circledR}$, que são dois softwares que geram um mosaico de palavras destacando as palavras mais frequentes nos textos de origem, servindo de apoio ao tratamento e melhor visualização dos resultados. Quanto à abordagem metodológica, a classificação se dará em conformidade ao julgamento dos autores de cada artigo, contudo as pesquisas que não expressam tais classificações serão apontadas como "Não Identificada". 


\section{Resultado}

Este tópico será dedicado a análise e a discussão dos resultados da pesquisa, encontra-se em cinco seções distintas para o melhor entendimento e demonstração dos dados bibliométricos descritos na metodologia.

\subsection{Quantificação dos Artigos}

A quantidade de artigos publicados nas seis edições do Congresso UFSC de Iniciação Científica em Contabilidade, realizados entre 2007 e 2015 foi no primeiro ano, vinte e cinco artigos, enquanto no último foram apresentados cento e quatro artigos, porém este aumento não foi gradativo (Tabela 1).

Tabela 1: Número de Artigos publicados no Congresso UFSC

\begin{tabular}{c|c|c|c|c|c|c|c}
\hline \multirow{2}{*}{ Congresso UFSC } & $1^{\circ}$ & $2^{\circ}$ & $3^{\circ}$ & $4^{\circ}$ & $5^{\circ}$ & $6^{\circ}$ & Total \\
\cline { 2 - 8 } & 2007 & 2008 & 2009 & 2011 & 2014 & 2015 & \\
\hline Iniciação Científica em Contabilidade & 25 & 23 & 26 & 70 & 66 & 104 & 314 \\
\hline Variação & - & $-8 \%$ & $13 \%$ & $169 \%$ & $-6 \%$ & $58 \%$ & \\
\hline Representatividade & $7,96 \%$ & $7,32 \%$ & $8,28 \%$ & $22,29 \%$ & $21,02 \%$ & $33,12 \%$ & $100 \%$ \\
\hline
\end{tabular}

Fonte: Autores (2017)

Observou-se que o último evento, realizado em 2015, foi o de maior representatividade $(33,12 \%)$ do total de 314 artigos. O menor número de publicações ocorreu no segundo evento com vinte e três artigos, representando $7,32 \%$ do total.

Relacionando com a pesquisa de Henrique Portulhak (2014), nota-se o aumento de publicações em Contabilidade, no primeiro ano analisado foram 16 artigos publicados e em 2013 foram 24 artigos, de um total de 99 publicações pela revista no período observado. A pesquisa de Santos (2015) corrobora com a análise apresentando um aumento de artigos publicados no decorrer dos anos coletados. Todavia, Anzilago et al. (2015) mostram uma queda na frequência de artigos apresentados no congresso em uma área específica de contabilidade durante o período analisado.

\subsection{Composição das Autorias}

A Tabela 2 aponta a dimensão de autoria dos artigos apresentados no Congresso UFSC de Iniciação Científica em Contabilidade. Foram relacionados 927 autores encontrados na totalidade dos artigos pesquisados. Observou-se como característica predominante o número de pesquisas constituídas por dois e três autores, 102 e 109, nesta ordem, representando 32,48\% e 34,71\% do total de artigos.

As demais observações apontam que há um predomínio de publicações realizadas em conjunto $(94,9 \%)$, visto que somente 16 pesquisas foram realizadas por apenas um autor, cerca de $5 \%$ de todo o total. As pesquisas com quatro autores também devem ser destacadas, pois evidenciam uma frequência de 66 artigos, sendo $21,02 \%$ do total de publicações. Enquanto, artigos com cinco e seis autores, representam $3,50 \%, 3,18 \%$, respectivamente. 
Tabela 2: Composição das Autorias

\begin{tabular}{c|c|c|c|c|c|c|c}
\hline Quantidade de Autores por artigo & $\mathbf{2 0 0 7}$ & $\mathbf{2 0 0 8}$ & $\mathbf{2 0 0 9}$ & $\mathbf{2 0 1 1}$ & $\mathbf{2 0 1 4}$ & $\mathbf{2 0 1 5}$ & Geral \\
\hline Um Autor & 2 & 0 & 1 & 9 & 0 & 4 & 16 \\
\hline Dois Autores & 7 & 7 & 5 & 26 & 23 & 34 & 102 \\
\hline Três Autores & 4 & 5 & 9 & 25 & 31 & 35 & 109 \\
\hline Quatro Autores & 4 & 5 & 8 & 6 & 12 & 31 & 66 \\
\hline Cinco Autores & 3 & 2 & 2 & 4 & 0 & 0 & 11 \\
\hline Seis Autores & 5 & 4 & 1 & 0 & 0 & 0 & 10 \\
\hline Total de Autores / Ano & 89 & 83 & 86 & 180 & 188 & 301 & 927 \\
\hline Total de Artigos & 25 & 23 & 26 & 70 & 66 & 104 & 314 \\
\hline Média de Autores Por Artigo & 3,56 & 3,61 & 3,31 & 2,57 & 2,85 & 2,89 & 2,95 \\
\hline
\end{tabular}

Fonte: Autores (2017)

A partir da Tabela 2 foi possível observar que a média de autores por artigo varia de 2,57 até 3,61 nos anos que compreendem o Congresso, e no total a média corresponde a 2,95 autores. Essa média corrobora com a predominância de artigos entre 2 e 3 autores.

Esta análise corrobora com as observações das pesquisas de Ribeiro (2013) e Leite Filho (2008). O primeiro autor demonstra uma média de 2,65 autores por artigo publicado no Congresso USP no período de 2001 a 2011. Enquanto a pesquisa de Leite Filho (2008) faz uma análise mais ampla, visto que a coleta de dados se deu em revistas e congressos. Em sua pesquisa o autor observou que nos periódicos destaca-se a autoria singular dos artigos, todavia nas publicações em congressos são apresentados trabalhos em coautorias, formando grupos de trabalhos numa frequencia relativa de três autores nos congressos, no período analisado.

Quanto ao gênero dos autores, a pesquisa diverge dos resultados observados dado que nos estudos apreciados há predominância de autores do sexo masculino, enquanto na pesquisa em questão existe o predomínio de autores do sexo feminino, como está evidenciado no gráfico abaixo onde estão dispostos os autores por sexo (Gráfico 1).

Gráfico 1: Autores quanto ao gênero

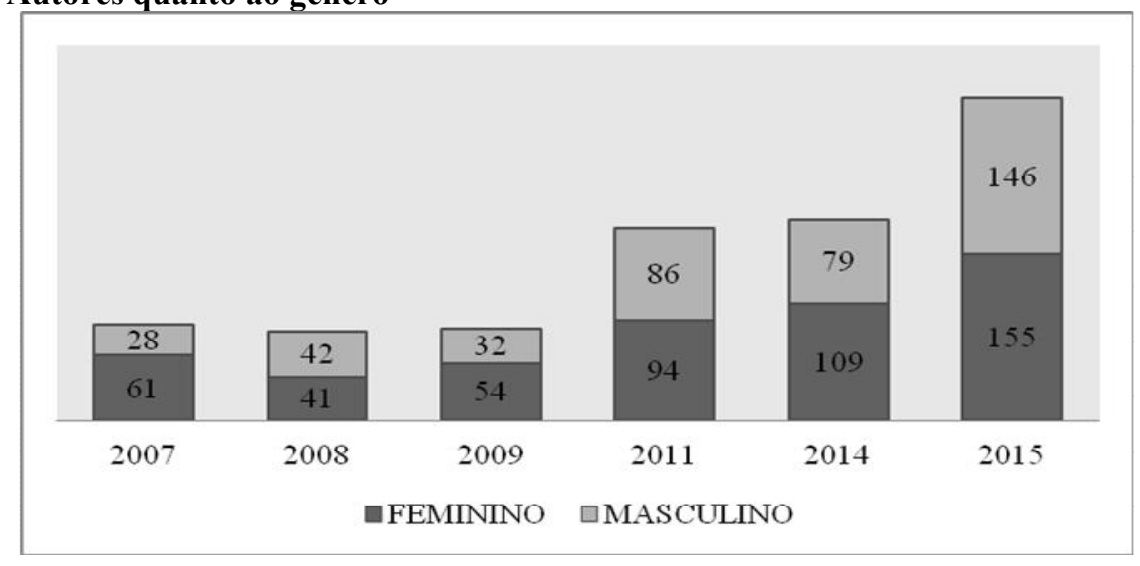

Fonte: Autores (2017) 
Como visto a predominância também está nas publicações com autores do sexo feminino representando mais 55\% do total das autorias dos artigos nesse Congresso. Sendo que em todos os anos do evento esteve em maioria, exceto por 2008 que esse número praticamente se igualou, sendo 41 mulheres e 42 homens.

\subsection{Disposição dos Autores}

Em face da composição de autoria, observa-se a disposição dos autores, expostas; as instituições de origens e a formação acadêmica dos autores, assim como a titulação e os autores mais prolíficos.

Foram 55 as instituições de origem dos artigos e é perceptível que a UFSC foi à instituição mais prolífica no Congresso UFSC Iniciação Científica em Contabilidade tendo 104 artigos publicados. Baseando-se nas demais pesquisas estudadas, nota-se que a UFSC está entre as 10 instituições mais produtivas em contabilidade do país.

Além da UFSC, a UFU publicou 46 artigos, UFES, 15 artigos, UNIVALI foram 14 artigos e a FURB publicou 10 artigos. As 50 demais instituições apresentaram menos de 10 artigos, como se observa a progressão negativa, além cinco artigos não identificada à origem pela ausência de informações no site do evento ou na Plataforma Lattes (Gráfico 2).

\section{Gráfico 2: Instituições mais prolíficas}

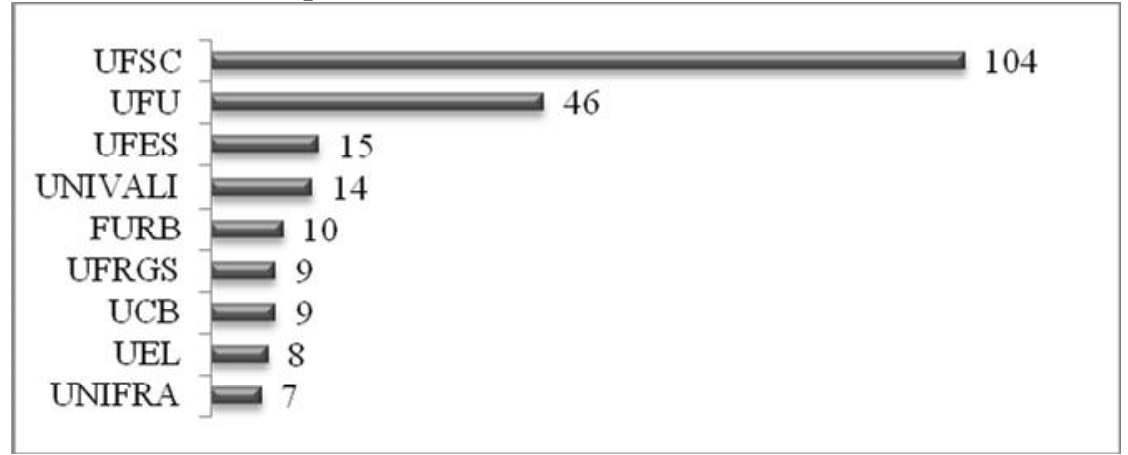

Fonte: Autores (2017)

A respeito da titulação máxima dos autores, exceto os 266 autores não identificados, observou-se que a maioria possui o Doutorado (24,81\%), na sequência $23,90 \%$ são estudantes de graduação, sendo 158 estudantes, possuem Mestrado (17,10\%), alunos do mestrado representam $12,10 \%$ e do doutorado $8,77 \%$, autores com especialização em alguma área superior consistem $6,35 \%$, e os que possuem graduação ou pós-doutorados completos constituem 4,08\% e 2,87\%, respectivamente (Gráfico 3). 
Gráfico 3: Titulação Máxima dos Autores

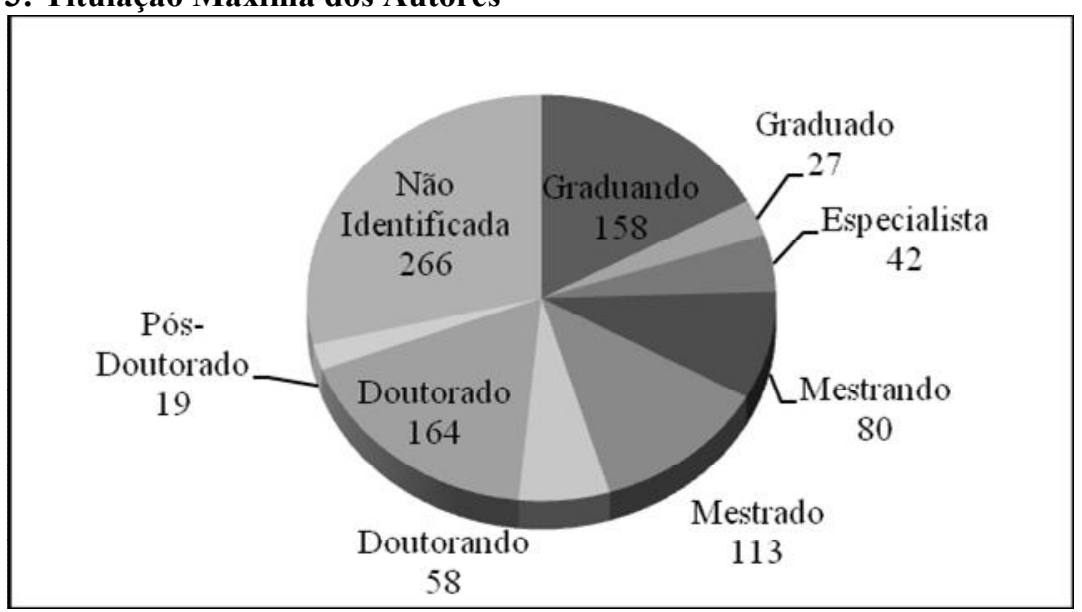

Fonte: Autores (2017)

Dos 927 autores descritos nos artigos, mais de 58\%, possuem formação acadêmica em Ciências Contábeis, entretanto em quase 30\% das autorias não foi possível constatar a formação, devido à ausência de informações tanto nos artigos quanto na Plataforma Lattes. Dentre os doutores, doutorandos e pós-doutores, o curso de Engenharia de Produção é o mais buscado $(33,61 \%)$, seguidos do curso de Administração (20,33\%) e Controladoria e Contabilidade $(11,20 \%)$.

Diante ao número de publicações de cada autor no Congresso, 573 autores apresentaram apenas um artigo em alguma edição do evento, 51 apresentaram dois artigos, 28 autores apresentaram três artigos, 12 publicaram quatro artigos e os vinte autores mais produtivos. Notase que as mais produtivas são Edvalda Araújo Leal e Sandra Rolim Ensslin ambas publicaram 11 artigos em quatro edições diferentes do Congresso; Elisete Dahmer Pfitscher, 10 artigos; Maria Denize Henrique Casagrande, 9 artigos e; Patrícia de Souza Costa e Sérgio Murilo Petri apresentaram 8 artigos, seguidos dos demais agentes prolíficos (Tabela 3).

Tabela 3: Autores mais Prolíficos

\begin{tabular}{l|c|c|c|c|c|c|c|c}
\hline \multicolumn{1}{c|}{ Autores Mais Prolíficos } & Instituição & $\mathbf{1}^{\circ}$ & $\mathbf{2}^{\circ}$ & $\mathbf{3}^{\circ}$ & $\mathbf{4}^{\circ}$ & $\mathbf{5}^{\circ}$ & $\mathbf{6}^{\circ}$ & $\mathbf{T O T}^{\prime}$ \\
\hline EDVALDA ARAÚJO LEAL & UFU & & 3 & 2 & 3 & 3 & 11 \\
\hline SANDRA ROLIM ENSSLIN & UFSC & 4 & 2 & 2 & 3 & & 11 \\
\hline ELISETE DAHMER PFITSCHER & UFSC & 2 & 2 & 1 & 3 & 2 & & 10 \\
\hline MARIA DENIZE HENRIQUE CASAGRANDE & UFSC & & 3 & 4 & 2 & & & 9 \\
\hline PATRÍCIA DE SOUZA COSTA & UFU & 2 & 2 & 1 & & 1 & 2 & 8 \\
\hline SÉRGIO MURILO PETRI & UFSC & & & 3 & 3 & 2 & 8 \\
\hline ORION AUGUSTO PLATT NETO & UFSC & & 2 & 3 & 1 & 1 \\
\hline CRISTIANO SAUSEN SOARES & UNIFRA & & & 3 & 1 & 2 \\
\hline ANDRÉIA CITTADIN & UFSC / UNESC & & 1 & 1 & 2 & 1 \\
\hline
\end{tabular}




\begin{tabular}{|c|c|c|c|c|c|c|c|c|}
\hline DONIZETE REINA & UFSC / UFES & & 1 & 2 & & & 2 & 5 \\
\hline FABRÍCIA SILVA DA ROSA & UFSC & 2 & & & & & 3 & 5 \\
\hline FLÁVIO DA CRUZ & UFSC & & & 2 & 2 & 1 & & 5 \\
\hline IDALBERTO JOSÉ DAS NEVES JÚNIOR & UCB & & & & 2 & 1 & 2 & 5 \\
\hline JOISSE ANTONIO LORANDI & UFSC & & & & 2 & 1 & 2 & 5 \\
\hline LUIZ FELIPE FERREIRA & UFSC & & 1 & & & 3 & 1 & 5 \\
\hline MARIA LUIZA GESSER DA SILVEIRA & UFSC & & & & 2 & 3 & & 5 \\
\hline SERGIO HENRIQUE CONCEIÇÃO & UNEB & & & & 2 & & 3 & 5 \\
\hline SULIANI ROVER & UFSC & & 1 & & & 3 & 1 & 5 \\
\hline
\end{tabular}

Fonte: Autores (2017)

Dentre as instituições, percebeu-se que a UFSC foi a instituição mais produtiva, diante dos autores mais prolíficos. A UFSC representa a origem de $65 \%$ desses autores, a UFU constitui 15 \% e a UNESC, a UCB, a UNEB e a UNIFRA constituem 5\% cada dessas proveniências.

\section{Assuntos e Linhas Temáticas}

Para analisar as Linhas Temáticas mais publicadas no Congresso, esta pesquisa utilizou-se da categorização dada pelo próprio evento, no qual os artigos foram relacionados e agrupados conforme as orientações do website do Congresso (Tabela 4).

Tabela 4: Linhas Temáticas conforme o website do Congresso

\begin{tabular}{c|c|c|c|c|c|c|c|c}
\hline LINHAS TEMÁTICAS & $\mathbf{2 0 0 7}$ & $\mathbf{2 0 0 8}$ & $\mathbf{2 0 0 9}$ & $\mathbf{2 0 1 1}$ & $\mathbf{2 0 1 4}$ & $\mathbf{2 0 1 5}$ & Geral & $\mathbf{9}$ \\
\hline CONTABILIDADE GERENCIAL & 4 & 6 & 5 & 15 & 19 & 33 & 82 & $26 \%$ \\
\hline FINANÇAS & 0 & 4 & 0 & 6 & 6 & 6 & 22 & $\mathbf{7} \%$ \\
\hline PESQUISA E ENSINO DA CONTABILIDADE & 0 & 4 & 6 & 8 & 9 & 13 & 40 & $13 \%$ \\
\hline DEMAIS TEMAS RELEVANTES & 0 & 8 & 14 & 37 & 23 & 44 & 126 & $40 \%$ \\
\hline OUTROS & 21 & 1 & 1 & 4 & 9 & 8 & 44 & $14 \%$ \\
\hline Total de Artigos & $\mathbf{2 5}$ & $\mathbf{2 3}$ & $\mathbf{2 6}$ & $\mathbf{7 0}$ & $\mathbf{6 6}$ & $\mathbf{1 0 4}$ & $\mathbf{3 1 4}$ & $\mathbf{1 0 0} \%$ \\
\hline
\end{tabular}

Fonte: Autores (2017)

$\mathrm{Na}$ Tabela 4, nota-se a classificação como Outros de 44 artigos, sendo que as linhas temáticas do Congresso não apresentam esta categoria, então se reclassificou esses artigos e obteve-se um novo resultado apresentado pelo Gráfico 4. 


\section{Gráfico 4: Linhas Temáticas}

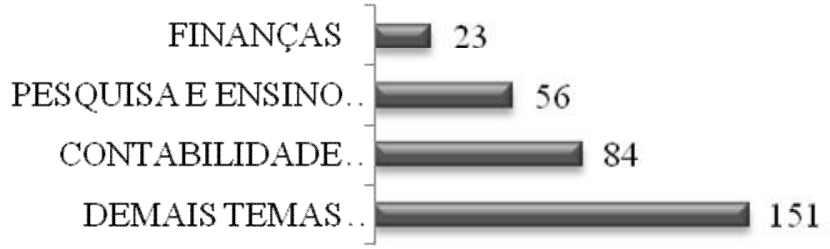

Fonte: Autores (2017)

Observa-se no Gráfico 4 a predominância de artigos classificados como Demais Temas Relevantes em Contabilidade, e o mesmo já verificado com predominância de $40 \%$ do total dos artigos. No Gráfico 4, ainda verifica-se que são 84 artigos com linhas de pesquisas na Contabilidade Gerencial, 56 artigos de Pesquisa e Ensino da Contabilidade e apenas 23 artigos que abordam a área de Finanças.

Dentro de cada tema, existem diversas subáreas temáticas, onde os artigos também foram classificados, dentre essas subáreas as dez mais publicadas estão apresentados pelo Gráfico 5 com seu número proporcional de publicações no Congresso, sendo que Contabilidade Pública Governamental tem sido o sub tema mais publicado $(8,28 \%)$. Dentre os dez subtemas mais publicados, esses representam quase $50 \%$ do total, sendo que existem mais de 50 classificações diferentes.

Gráfico 5: Sub Áreas Temática com mais publicação

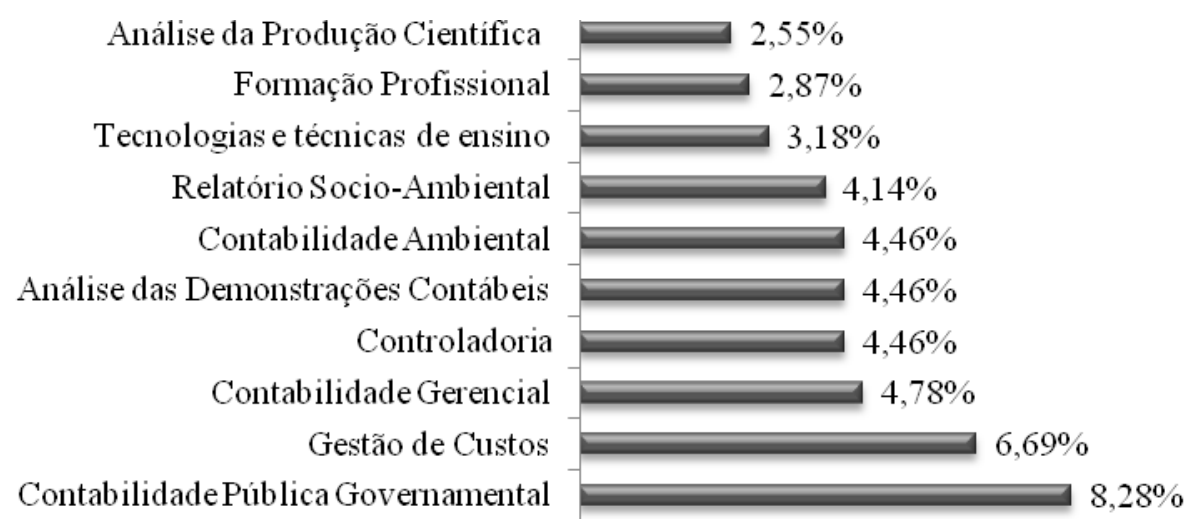

Fonte: Autores (2017)

Para melhor entendimento da classificação das linhas temáticas, foram explanadas na Tabela 5, as subáreas temáticas do Congresso, apresentando os principais focos das pesquisas acolhidas pelo Congresso, excluindo as linhas que não foram apresentadas ao menos um artigo.

Tabela 5: Classificação das Sub Áreas Temáticas conforme o site do Congresso UFSC

\begin{tabular}{|c|c|c|}
\hline Tema & Sub Área Temática & Total \\
\hline OUTROS & Outros & 44 \\
\hline 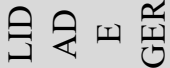 & BSC (Balanced Scorecard) & 2 \\
\hline
\end{tabular}




\begin{tabular}{|c|c|c|}
\hline & Contabilidade Gerencial & 15 \\
\hline & Controladoria em Entidades Públicas & 2 \\
\hline & Controladoria para Gestão de Processos de Logística Integrada & 1 \\
\hline & Controladoria & 14 \\
\hline & Controle Financeiro, Tributário e Gerencial & 5 \\
\hline & Gestão Estratégica (Planejamento e Controle Empresarial) & 5 \\
\hline & Gestão de Custos & 21 \\
\hline & Indicadores de Desempenho & 2 \\
\hline & Métodos de custeio & 1 \\
\hline & Modelos de Mensuração e Avaliação do Desempenho Empresarial & 3 \\
\hline & Planejamento Tributário & 6 \\
\hline & Tecnologia e Sistemas de Informação & 5 \\
\hline & Avaliação de empresas & 8 \\
\hline & Avaliação de Investimentos & 2 \\
\hline & Finanças Corporativas, de curto e longo prazo & 1 \\
\hline Z & Finanças Pessoais & 4 \\
\hline 壱 & Finanças Públicas Municipais & 2 \\
\hline & Governança Corporativa & 1 \\
\hline & Mercado de capitais & 4 \\
\hline & Tecnologias e técnicas de ensino & 10 \\
\hline & Metodologia de pesquisa & 5 \\
\hline 觉 & Ética & 2 \\
\hline 正 & Formação Profissional & 9 \\
\hline 岕艺 & Análise da Produção Científica nas áreas de conhecimento das Ciências Contábeis & 8 \\
\hline$\approx 0$ & Avaliação: de Cursos, do Processo Ensino-Aprendizagem, Institucional & 5 \\
\hline-4 & Ensino a distância & 1 \\
\hline 舀 寻 & Análise das Demonstrações Contábeis & 14 \\
\hline$\sum_{i} \sum_{i=1} \bar{m}$ & Auditoria Contábil (Interna e independente) & 4 \\
\hline 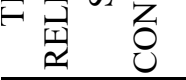 & Balanço Social (DVA, Ambiental, Capital Intelectual) & 6 \\
\hline
\end{tabular}




\begin{tabular}{|c|c|}
\hline Contabilidade Internacional e Comparada & 4 \\
\hline Contabilidade no Agrobusiness & 6 \\
\hline Contabilidade para Pequenas e Médias Empresas & 4 \\
\hline Contabilidade Pública Governamental & 26 \\
\hline Contabilidade Pública Não Governamental (OSCIPs) & 6 \\
\hline Contabilidade Societária & 7 \\
\hline Contabilidade Tributária & 6 \\
\hline Harmonização das normas contábeis & 4 \\
\hline Métodos Quantitativos Aplicados à Contabilidade & 2 \\
\hline Padronização das normas contábeis & 1 \\
\hline Perícia Contábil & 1 \\
\hline Responsabilidade Social e Ambiental & 4 \\
\hline Teoria da Contabilidade & 4 \\
\hline Contabilidade Ambiental & 14 \\
\hline Relatório Socioambiental & 13 \\
\hline
\end{tabular}

Fonte: Autores (2017)

Nota-se por meio da Tabela 5 a predominância de artigos categorizados nos "Demais Temas Relevantes em Contabilidade", seguido por "Contabilidade Gerencial", porém dentre essas categorias há subtemas pouco exploradas, sendo linhas de pesquisas tão importantes quanto os mais publicados, porém estão poucos evidenciados neste Congresso.

Com relação às palavras-chaves descritas nos artigos, há cinco artigos que não identificaram suas palavras-chaves, no total foram apresentados 1074 termos chaves nos artigos, ocorrendo à predominância de artigos com três palavras-chaves, sendo 200 artigos com essa característica. " $\mathrm{O}$ conjunto de palavras-chave foi tratado com a utilização do software Microsoft Excel ${ }^{\circledR} \mathrm{e}$, com apoio do software on-line Wordle.net ${ }^{\circledR}$ (http://www.wordle.net/), foi elaborada uma representação desse conjunto de palavras em forma de mosaico (ou nuvem)" (PORTULHAK, 2014, p.413), a Figura 6 representa a visualização desse estudo bibliométrico. 


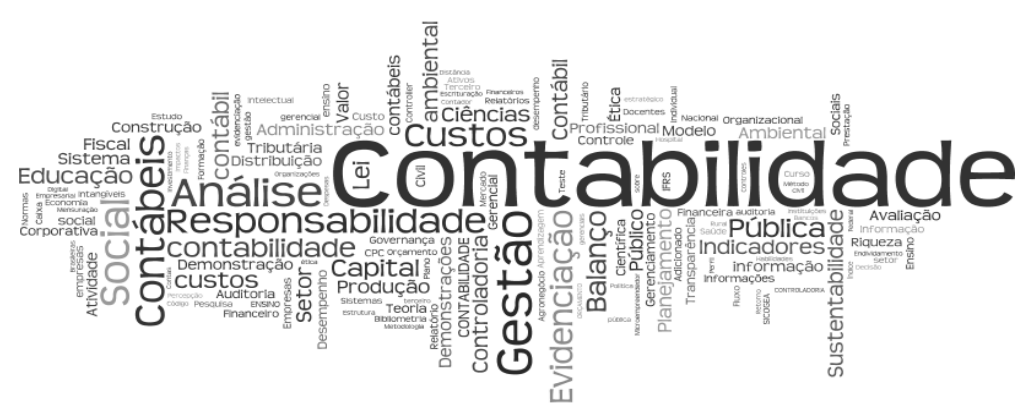

Fonte: Autores (2017)

Com o auxílio da ferramenta Tagul.com $^{\circledR}$ (http://www.tagul.com) é possível verificar a frequência das palavras mais citadas nesse quesito, como observado no Gráfico 6 a palavra "contabilidade" é a mais repetida dentre as palavras-chave, citada 68 vezes, seguidas das seguintes palavras "custo" (35 ocorrências), "contábeis" (29), "gestão" (29), "social” (25), "ambiente" (24), "contábil” (22), "análise” (21), "pública” (20) e "evidenciação" (19), sendo essas as dez palavras mais frequentes. Ressaltando ainda que essa análise verifica as palavras de forma individual, não considera as expressões como destacado nas palavras-chave dos artigos.

Na pesquisa de Ribeiro (2013, p.733-734), as palavras-chaves mais citadas são "custos, contabilidade, controladoria, gestão, gerencial, desempenho, responsabilidade e orçamento”. Já nos estudos de Portulhak (2014, p.413), as palavras-chaves mais frequentes são "contabilidade, contábil, gestão, desempenho, contábeis, corporativa, governança, setor, custos, evidenciação, ambiental e financeiros", podendo observar-se que algumas delas repetem-se independente da pesquisa.

\subsection{Abordagens Metodológicas}

Nesta seção, será descrito as abordagens mais utilizadas pelos autores nas publicações do Congresso UFSC Iniciação Científica em Contabilidade, onde será apresentado o enquadramento metodológico com relação ao problema e ao objetivo das pesquisas empreendidos pelos próprios autores. Em alguns estudos, onde alguma dessas classificações não foi feita, o enquadramento será enunciado como "Não identificado pelos autores".

Após toda a investigação, artigos com abordagem qualitativa com relação ao problema de pesquisa tiveram predominância nesta classificação, representando $37,9 \%$ de todo o total de artigos, seguidos pela abordagem quantitativa com 30,25\%, e quali-quantitava com 17,20\%. Porém, o número de artigos que não apresentam nenhum enquadramento representa 14,65\%, sendo 46 artigos sem nenhuma definição de abordagem (Gráfico 7).

A pesquisa corrobora com o estudo feito por Anzilago et al. (2015) onde a maioria das publicações utilizaram-se da abordagem qualitativa, contudo diverge das pesquisas de Portulhak 
(2014), Ribeiro (2013) e Santos (2015), onde em seus estudos os autores observaram que abordagem quantitativa foi a mais usual.

Gráfico 7: Abordagem em relação ao problema

Fonte: Autores (2017)

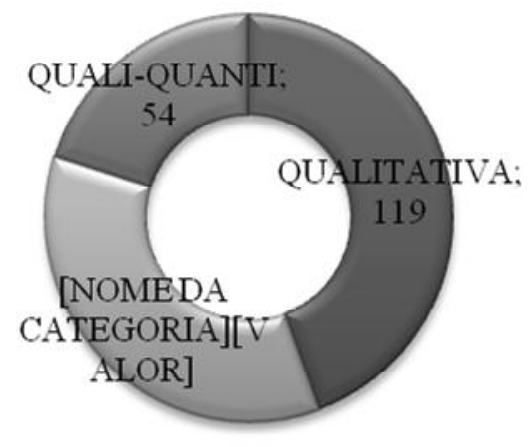

Artigos com o enquadramento metodológico descritivo com relação ao objetivo de pesquisa é a maioria, sendo utilizada por mais 53\% das autorias. Sendo utilizada a abordagem exploratória em 19,75\%, e exploratória-descritiva conjuntamente em 12,10\%. Os autores utilizaram abordagem explicativa e explicativa-descritiva em $0,64 \%$ dos artigos e apenas um artigo foi enquadrado por seus autores com as três abordagens, ainda 40 artigos não possuíram nenhuma classificação por seus autores (Tabela 6). O resultado corrobora com a pesquisa de Portulhak (2014), onde em 55,2\% dos artigos coletados empregou-se a abordagem descritiva.

Tabela 6: Abordagem em relação ao objetivo, identificada pelos autores

\begin{tabular}{|c|c|c|c|c|c|c|c|}
\hline Abordagem em relação ao objetivo & 2007 & 2008 & 2009 & 2011 & 2014 & 2015 & Geral \\
\hline DESCRITIVA & 7 & 9 & 10 & 32 & 52 & 59 & 169 \\
\hline EXPLORATÓRIA & 9 & 4 & 13 & 22 & 4 & 10 & 62 \\
\hline EXPLICATIVA & 0 & 1 & 0 & 0 & 0 & 1 & 2 \\
\hline EXPLORATÓRIA-DESCRITIVA & 5 & 3 & 2 & 7 & 7 & 14 & 38 \\
\hline EXPLICATIVA-DESCRITIVA & 0 & 0 & 0 & 0 & 0 & 2 & 2 \\
\hline DESCRITIVA/EXPLORATÓRIA/EXPLICATIVA & 0 & 0 & 0 & 0 & 0 & 1 & 1 \\
\hline NÃO IDENTIFICADA PELOS AUTORES & 4 & 6 & 1 & 9 & 3 & 17 & 40 \\
\hline Total de Artigos & 25 & 23 & 26 & 70 & 66 & 104 & 314 \\
\hline
\end{tabular}

Fonte: Autores (2017)

Destacando que esta investigação foi feita de forma quantitativa, logo não foi feito enquadramento metodológico desses artigos "não identificados pelos autores", foram observados dados expressamente mencionados pelos autores para que não houvesse uma subjetividade na classificação destes. 


\section{Considerações Finais}

O presente estudo teve como objetivo principal identificar o perfil das publicações do Congresso UFSC Iniciação Científica em Contabilidade. Por meio de uma pesquisa bibliográfica, predominantemente quantitativa e bastante descritiva, foram definidos os seguintes objetivos específicos: (i) a quantidade de artigos, (ii) as linhas de pesquisas mais recorrentes, (iii) as instituições mais produtivas, bem como (iv) as metodologias aplicadas nos artigos.

Os resultados mostraram que foram 314 artigos apresentados no determinado Congresso, com um total de 927 autores e uma média de 2,95 autores por artigo. As linhas de pesquisas mais recorrentes estão definidas como "Demais Temas Relevantes Em Contabilidade", onde a Contabilidade Pública Governamental é o subtema mais frequente.

Em referência a titulação máxima dos autores, observou-se 266 autores não identificados na pesquisa, devido a utilização da Plataforma Lattes na qual os graduandos não possuem obrigatoriedade de manter um currículo atualizado. Tratando-se de um estudo realizado sobre um Congresso de Iniciação Científica, identificou-se um total de 424 autores como sendo estudantes de graduação, representando assim, mais de $45 \%$ das autorias das publicações do Congresso pesquisado.

Foram 56 instituições que apresentaram artigos no Congresso, a UFSC (SC) foi a instituição mais produtiva com 104 artigos apresentados, seguida pela UFU (MG) com 46 artigos. Foi observado que as autoras mais prolíficas são Edvalda Araújo Leal e Sandra Rolim Ensslin ambas publicaram 11 artigos em quatro edições diferentes do Congresso. Com relação à abordagem de pesquisa a mais utilizada foi a qualitativa (119) com relação ao problema e descritiva (169) relacionada ao objetivo.

Conclui-se com esta pesquisa que há temas em Contabilidade para serem explorados pelos futuros pesquisadores, avançando na produção científica e na disseminação do conhecimento. Ainda há espaço para projetos multidisciplinares ampliando a produção intelectual dado que os resultados apontaram que a maior parte dos artigos foi realizada exclusivamente por autores formados ou em formação contábil.

Considerando as limitações da pesquisa, por utilizar como amostra os anais do Congresso UFSC Iniciação Científica em Contabilidade, alerta-se que seus resultados não podem ser generalizados. Como sugestões para futuras pesquisas, recomenda-se que sejam feitos estudos que englobam todos os periódicos e anais de congresso ou pesquisas em outros congressos nacionais ou internacionais e comparar seus resultados. 


\section{Referências}

ANZILAGO, Marcielle; SANTOS, Edicreia Andrade; DACIÊ, Franciele do Prado; BEZERRA, Cícero Aparecido. O perfil das publicações da Conferência do Centre for Social \& Environmental Accounting Research - CSEAR. CSEAR South America Conference, Brasil, mai. 2015.2 Disponível em: $<$ http://www.csearsouthamerica.net/events/index.php/csear/CSEAR2015/paper/view/172>. Acesso em: 10/05/2016.

ARAUJO, Alessandra Rodrigues Machado de; FERREIRA, Luiz Felipe; FERREIRA, Denize Demarche Minatti; CAMINHA, Rafael Gloria.. Governança Ambiental: Análise da Produção Científica em Periódicos entre 2002 e 2014. CSEAR South America Conference, Brasil, mai. 2015. Disponível

em: $<$ http://www.csearsouthamerica.net/events/index.php/csear/CSEAR2015/paper/view/147>. Acesso em: 10/05/2016

ARAÚJO, $\operatorname{Carlos} A$ A. Bibliometria: evolução histórica e questões atuais. Em Questão, Brasil, v. 12, n. 1, 2007. Disponível em: <http://seer.ufrgs.br/index.php/EmQuestao/article/view/16>. Acesso em: 18/06/2016

BORBA, J. A.; MURCIA, F. D. R. Oportunidade para Pesquisa e Publicação em Contabilidade: um estudo preliminar sobre as revistas acadêmicas de língua inglesa do Portal de Periódicos da CAPES. VI Congresso USP de Controladoria e Contabilidade, São Paulo, 2006. Anais... 2006.

BRUNOZI JÚNIOR, Antônio Carlos; EMMENDOERFER, Magnus Luiz; ABRANTES, Luiz Antônio; KLEIN, Thiara Contelli. Revista Contabilidade \& Finanças - USP: uma análise do perfil da produção científica de 1989 a 2009. Revista Universo Contábil, v. 7, n. 4, p. 39-59, 2011. Disponível em: < http://proxy.furb.br/ojs/index.php/universocontabil/article/view/1666>. Acesso em: 18/06/2016

CAMPOS, M. Conceitos atuais em bibliometria. Arquivos Brasileiros Oftalmologia, 66(1), 122, 2003.

CARDOSO, Ricardo Lopes; MENDONÇA NETO, Octávio Ribeiro de; RICCIO, Edson Luiz; Sakata, Marici Cristine Gramacho. Pesquisa científica em contabilidade entre 1990 e 2003. RAE - Revista de Administração de Empresas, v. 45, n. 2, p. 34-45, jan. 2005. Disponível em: $<\mathrm{http} / / /$ bibliotecadigital.fgv.br/ojs/index.php/rae/article/view/37114/35885>. Acesso em: $18 / 06 / 2016$

CASAGRANDE, M. D. H; ROSA, C. A.; BORBA, J. A.; PFITSCHER, E. D. Produção científica e a disseminação de conhecimento: um estudo da contribuição dos docentes na orientação de trabalhos de conclusão de curso de ciências contábeis da universidade federal de Santa Catarina nos anos de 2008 e 2009. Revista Jovens Pesquisadores, v. 9, n. 2, p. 52-68, 2012. Disponível

em: 
$<$ http://www.mackenzie.br/dhtm/seer/index.php/jovenspesquisadores/article/view/1189>. Acesso em: $23 / 05 / 2016$

CERVO, Amado L.; BERVIAN, Pedro A.; SILVA, Roberto da. Metodologia científica. 6. ed. São Paulo: Pearson Prentice Hall, 2007.

CHUEKE, G. V.; AMATUCCI, M. O que é bibliometria? Uma introdução ao Fórum. InternexT - Revista Eletrônica de Negócios Internacionais da ESPM, v. 10, n. 2, p. 1-5, 2015. Disponível em: <http://www.spell.org.br/documentos/ver/37400>. Acesso em: 23/05/2016

CUNHA, J. V. A.; CORNACHIONE, E. B., Jr.; MARTINS, Gilberto de Andrade. Contribuições científicas dos doutores em Ciências Contábies: Uma análise dos curriculos Lattes. Revista Universo Contábil, v. 7, p. 85-96, 2011.

FERREIRA, Denize Demarche Minatti; ROSA, Carolina Aguiar da; BORBA, José Alonso. Panorama e potencialidades para publicação de artigos científicos na área ambiental. Raep, v. 13, n. 4, p.673-705, 31 dez. 2012. Disponível em: $<$ https://raep.emnuvens.com.br/raep/article/view/78/108>. Acesso em: 10/05/2016

FIGUEIREDO, Nice. Da importância dos artigos de revisão da literatura. Revista Brasileira de Biblioteconomia e Documentação, São Paulo, v. 23, n. 1/4, p. 131-135, jan./dez. 1990.

FREZATTI, Fábio; BORBA, José Alonso. Análise dos traços de tendência de uma amostra das revistas científicas da área de contabilidade publicadas na língua inglesa. Cadernos de Estudos, São Paulo, n. 24, p. 50-78, dez. 2000. Disponível em: $<$ http://www.revistas.usp.br/cest/article/view/5661/7192>. Acesso em: 18/06/2016

GIL, Antonio Carlos. Como elaborar projetos de pesquisa. 5. ed. São Paulo: Atlas, 2010.

LEITE FILHO, Geraldo Alemandro. Padrões de produtividade de autores em periódicos e congressos na área de contabilidade no Brasil: um estudo bibliométrico. Rev. adm. contemp., Curitiba , v. 12, n. 2, p. 533-554, jun. $2008 . \quad$ Disponível em $<$ http://www.scielo.br/scielo.php?script=sci_arttext\&pid=S141565552008000200011\&lng=pt\&nrm=iso > . Acesso em: 18/06/2016

LUCA, Márcia Martins Mendes De; GOMES, Carlos Adriano Santos; CORRÊA, Denise Maria Moreira Chagas; DOMINGOS, Sylvia Rejane Magalhães. Participação feminina na produção científica em contabilidade publicada nos anais dos Eventos Enanpad, Congresso USP de Controladoria e Contabilidade e Congresso ANPCONT. Revista de Contabilidade e Organizações, v. 5, n. 11, art. 8, p. 145-164, 2011. Disponível em: $<$ http://www.revistas.usp.br/rco/article/view/34790>. Acesso em: 18/06/2016

MACHADO, Débora Gomes; SILVA, Tarcísio Pedro da; BEUREN, Ilse Maria. Produção científica de custos: análise das publicações em periódicos nacionais de contabilidade sob a perspectiva das redes sociais e da bibliometria. Contabilidade, Gestão e Governança, v. 15, n. 
3, p. 3-16, 2012. Disponível em: <https://cgg-amg.unb.br/index.php/contabil/article/view/404>. Acesso em: 18/06/2016

MENDONÇA NETO, $\mathrm{O}$ et. al. Estudo sobre as sobre as publicações cientificas em contabilidade: uma análise de 1990 até 2003. Encontro da Anpad, 28, 2004. Anais... XXVIII Encontro da Anpad. Curitiba, 2004.

MICHEL, Maria Helena. Metodologia e pesquisa científica em ciências sociais. 2. ed. São Paulo: Atlas, 2009.

OKUBO, Y. Bibliometric indicators and analysis of research systems: methods and examples. Paris: OECD, 1997. 69 p. (STI Working Papers, 1997/1).

OLIVEIRA, Elayne Karinna Figueiredo de; BOENTE, Diego Rodrigues. Análise bibliométrica da produção científica recente sobre contabilidade gerencial. Revista Organizações em Contexto, v. 8, n. 15, p. 199-212, 2012. Disponível em: $<$ https://www.metodista.br/revistas/revistasmetodista/index.php/OC/article/viewFile/2879/pdf_48>. Acesso em: 18/06/2016

OLIVEIRA, Marcelle Colares. Análise dos periódicos Brasileiros de contabilidade. Revista Contabilidade \& Finanças, v. 13, n. 29, p. 68-86 , aug. 2002. Disponível em: $<$ http://www.revistas.usp.br/rcf/article/view/34075/36807>. Acesso em: 18/06/2016

PORTULHAK, Henrique. Revista de Contabilidade e Controladoria (RC\&C): Análise dos Cinco Primeiros Anos de Publicação (2009-2013). REPeC - Revista de Educação e Pesquisa em Contabilidade, Brasília, v. 8, n. 4, art. 4, p. 403-419, out./dez. 2014. Disponível em: $<$ http://www.repec.org.br/index.php/repec/article/view/1093>. Acesso em: 23/05/2016

RIBEIRO, Henrique César Melo. Contribuição do congresso USP ao estudo da área temática controladoria e contabilidade gerencial: uma bibliometria. RACE: Revista de Administração, Contabilidade e Economia, v. 12, n. 2, p. 709-746, 2013. Disponível em: $<$ http://editora.unoesc.edu.br/index.php/race/article/view/2371>. Acesso em: 23/05/2016

SANTOS, Geovane Camilo dos. Análise Bibliométrica dos Artigos Publicados como Estudos Bibliométricos na História do Congresso Brasileiro de Custos. Pensar Contábil, v. 17, n. 62, p. 4-13, 2015. Disponível em: <http://www.spell.org.br/documentos/ver/37276/analisebibliometrica-dos-artigos-publicados-como-estudos-bibliometricos-na-historia-do-congressobrasileiro-de-custos-/i/pt-br>. Acesso em: 23/07/2016

SILVA, A. C. B.; OLIVEIRA, E. C. de; RIBEIRO FILHO, J. F.. Revista Contabilidade e Finanças USP: uma comparação entre os períodos 1989/2001 e 2001/2004. Revista Contabilidade e Finanças, n.43, p. 20-32. Out/Dez, 2005.

SILVA, Harley Almeida Soares da; REINA, Diane Rossi Maximiano; ENSSLIN, Sandra Rolim; REINA, Donizete. Programas de pós-graduação em contabilidade: Análise da produção científica e redes de colaboração. Revista de Contabilidade e Organizações, v. 6, n. 14, p. 145 - 
162, apr. 2012. Disponível em: <http://www.revistas.usp.br/rco/article/view/45420>. Acesso em: $18 / 06 / 2016$

SOUZA, A. A.; AVELAR, E. A.; BOINA, T. M.; TEIXEIRA, L. R. Ensino da Contabilidade Gerencial: estudo dos cursos de Ciências Contábeis das melhores universidades brasileiras. Revista de Contabilidade Contemporânea, v. 5, n. 10, p. 69-90, 2008.

VANTI, Nadia Aurora Peres. Da bibliometria à webometria: uma exploração conceitual dos mecanismos utilizados para medir o registro da informação e a difusão do conhecimento. Ciência da Informação, v. 31, n. 2, oct. 2002. Disponível em: $<$ http://revista.ibict.br/ciinf/article/view/970>. Acesso em: 24/07/2016. 